\title{
Üniversite Öğrencilerinin İletişim Kavramına Yönelik Metaforik Algıları ${ }^{1}$
}

\section{University Students’'Metaphorical Perception about the Concept of Communication}

\author{
Sevda KOÇ AKRAN \\ Siirt Üniversitesi, Eğitim Fakültesi, Eğitim Bilimler Bölümü, Siirt \\ e-posta: sevdakc@gmail.com \\ Merve ACIDEMIR \\ Siirt Üniversitesi, Sınıf Öğretmenliği Bölümü Öğrencisi \\ Şevval ULUDAĞ \\ Siirt Üniversitesi, Sınıf Öğretmenliği Bölümü Ö̆grencisi
}

\begin{abstract}
Atıf: Koç Akran, S., Acıdemir, M., \& Uludağ, Ş. (2018). Üniversite Öğrencilerinin İletişim Kavramına Yönelik Metaforik Algıları. E-Kafkas Ĕ̆itim Araştırmaları Dergisi, 5(2), 69-82.
\end{abstract}

Gönderi Tarihi: 06-07-2018

Kabul Edilme Tarihi: 30-07-2018

DOI: $10.30900 /$ kafkasegt.441228

$\ddot{O z e t}$

$\mathrm{Bu}$ araştırmanın temel amacı, üniversite öğrencilerinin iletişim kavramına yönelik metaforik algılarını belirlemektir. Nitel araştırma yönteminin kullanıldığı araştırmanın çalışma grubunu, Siirt Üniversitesinde öğrenim gören İktisadi ve İdari Bilimler, Fen Edebiyat, Eğitim, İlâhiyat, Veterinerlik Fakültesi, Beden Eğitimi ve Spor Yüksek Okulu, Sağlık Yüksekokulu, Yabancı Diller Yüksekokulu ve Mühendislik Fakültesi bölümündeki 340 öğrenci oluşturmaktadır. Verilerin analizinde frekans, yüzde, betimsel ve içerik analiz yöntemi kullanılmışır. Araştırma sonuçlarına göre, katılımcıların iletişim kavramına yönelik üretmiş oldukları metaforlar sırasıyla en çok "Temel ihtiyaç", "Bilgi kaynağı", "Doğa olayları", "İletişim" "Uzunluk", "Sonsuz olma'; en az ise "Ulaş1lması gereken yer", "Ahenk içinde olma”, "Coğrafya", "Taşıltar" ve "Kötü”dür. Anahtar Kelimeler: Eğitim, İletişim, İletişim Becerileri

\begin{abstract}
The main aim of this research is determine university students' metaphorical perception about the concept of communication. The study group of the research in which the qualitative research is used is composed of 340 students attending Siirt University in the department of Economics and Administrative Sciences, Faculty of Arts and Sciences, Faculty of Education, Department of Theology, Veterinary, Medicine, Physical Education and Sports, Siirt School of Health, School of Foreign Languages, Interpreting and Engineering Department. In the analysing of the data, frequency, percentage, descriptive analysis and content analysis method were used. Accordind to results, the participants' metaphors for the concept of communication respectively and the most belong to categories of "Basic need", "Information source", "Nature events", "Communication" "Length", "Being infinite"; at least "Place to be reached", "To be in harmony", "Geography", "Vehicles" and "Bad".
\end{abstract}

Keywords: Education, Communication, Communication Skills.

\section{GíRiș}

Eğitim, yaşam boyu devam eden, bireyi birçok yönüyle ele alan ve toplumun kalkınmasında önemli rol oynayan uzun bir süreçtir. Eğitim sürecinde bireye yol gösteren ona yardımcı olan ve toplumun önemli bir bireyi olmasını sağlayan kişiler bulunmaktadır. Bunlar aile ve öğretmendir. Aile, çocuğun ilk dünyaya geldiği andan itibaren ona karşı görevleri yerine getirmekle yükümlü olan (Doğan, 2013), bireyin sosyalleşmesi yolunda adımlar atılmasını sağlayan, topluma sağlıklı bireylerin yetiştirilmesinde öncü görevleri olan informal eğitim yuvasıdır. Başka bir deyişle, bireyin beslenmesinden, bir meslek sahibi olmasına, aile kurmasına kadarki süreçte bireyi yalnız bırakmayan bir kurumdur. Bireyin kişiliğinde, ahlaki değerlerin kazandırılmasında rol oynayan toplumun en küçük yapıtaşıdır (Avşaroğlu, 2011 ve Özkan, 2004). Aile toplumun bu değer ve normlarını birey yoluyla başka toplumlara aktaran/tanıtan köprüdür (Akın ve Aydemir, 2007). Aileye yüklenen bu görevler ve tanımlar tarih boyunca bu şekilde ilermiş ve günümüze kadar devam etmiştir. Çünkü birey konuşmayı,

\footnotetext{
${ }^{1}$ Bu çalışma 26-27 Nisan 2018 tarihinde, Siirt Üniversitesinde düzenlenen I. Sosyal Bilimler Öğrenci Sempozyumunda Sözlü Bildiri Olarak sunulmuştur.
} 
dinlemeyi, değerleri, işbölümü (Baran, 2013) ve toplumda saygın bir birey olmasına sağlayan birçok beceriyi aile ortamında öğrenmektedir. Bireyin bu öğrenme sürecinde öğrendiği en temel becerilerin başında iletişim gelmektedir. İletişim, bireyin duygu ve düşüncelerinin karşıdaki insana aktarılmasıdır (Ergen, 2001). Bireyler arasında kurulan, karşılıklı etkileşimdir. Her bireyin yaşamını devam ettirmesinde yardımcı olan temel bir ihtiyaçtır. Bu sebeple birey, iletişim sürecini iyi bilmeli, ne zaman? nerede? nasıl? davranacağını planlamalı ve davranışlarını ona göre yapılandırmalıdır. İletişim sürecinde bu durum bireyin diğer bireyler üzerindeki etkisini belirlemektedir. Örneğin beden dili iletişimin vazgeçilmez sürecidir. Öğretmenler ve aileler konuşarak bireye birçok bilgi ve beceriyi aktarmaya çalışmaktadır. Fakat bazen birçok kelimenin anlatamadığı ve ya vermek istediği mesajı tek bir beden dili ile bireye aktarabilirsiniz. (Bkz: şekil 1-2-3-4-5).
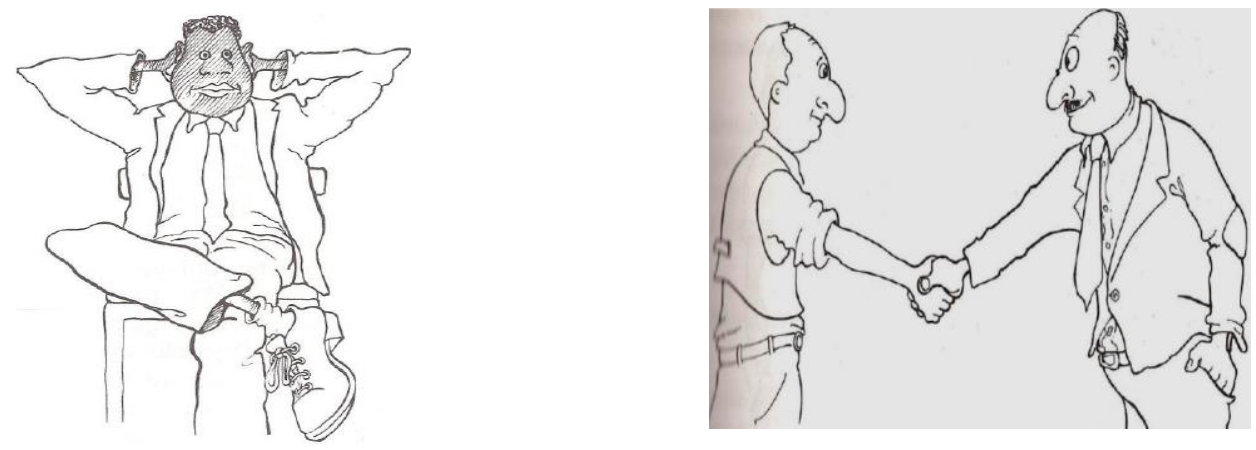

Şekil 1. Her iki el başın arkasında (Üstünsel, 2011). Şekil 2. Kırsal kesimde yaşayan iki kişinin selamlaşması(Üstünsel, 2011).
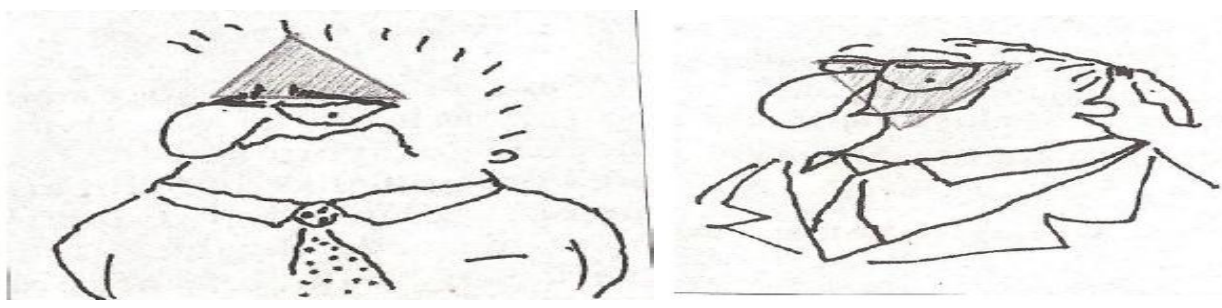

Şekil 3. Resmiyet baklşı (Üstünsel, 2011).

Şekil 4. İletişim bakışı (Üstünsel, 2011).
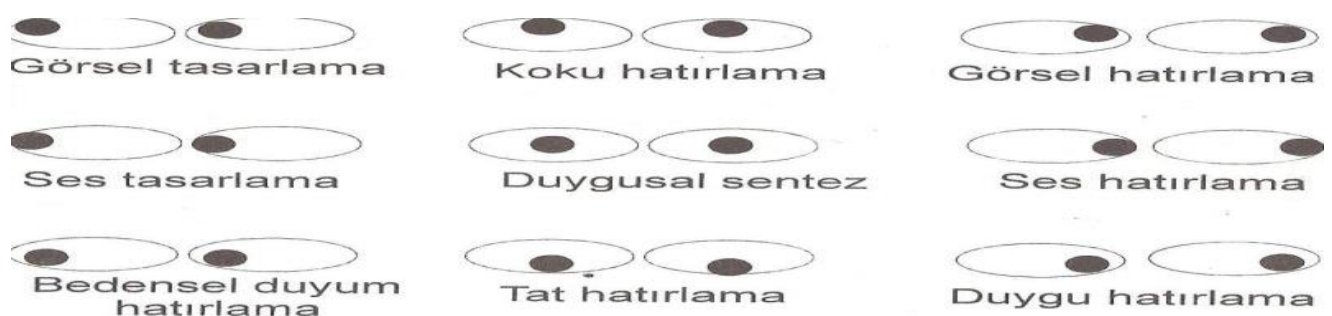

Şekil 5. Göz hareketleri ve anlamları (Üstünsel, 2011).

İnsanlar beden dili ile iletişime açık katılım gösterirler. Şekil 1'de görüldüğü üzere, iki elini başının arkasına koyan birey, bilginin ve çözümün kendisinde olduğunu, kontrolü sağladığını vurgulamaktadır. Şekil 2 'de birey iletişim kurarken, beden dili ile rahatlı̆̆ın ve karşılıklı samimiyetin olduğunu göstermektedir. Şekil 3'de disiplin, şekil 4'de ise karşıdaki bireyle iletişim kurmak istediği izlenimi verilmektedir. Son olarak şekil 5'de göz hareketleri ve onların ne? anlama geldiği gösterilmektedir. Şekillerde görülen beden dillerinin birçoğunu birey aile ortamında anne, baba ve diğer aile bireylerini model alarak öğrenmektedir. Aile içinde öğrendiği bilgi ve becerilerini birey günlük yaşamda öğretmeniyle, arkadaşlarıyla sürdürmektedir. Burada aile kadar bireye yakın olan, bireyi tanıyan, onun ihtiyaçlarını karşılayan ve formal olarak bireye eğitim veren 
öğretmeninde bu sebeple bazı görevleri bulunmaktadır. Çünkü eğitim öğretim ortamı düşünüldüğünde iletişim sürecinin temel öğelerinden birinin öğretmen olduğu görülmektedir. Öğretmenin, insan ilişkilerinde ve iletişiminde etkisi göz ardı edilmeyen bir gerçektir. Öğrenme sürecinde iletişimi başlatan kişi diğer bir ifade ile kaynak büyük oranda öğretmendir (Çiftçi ve Taşkaya, 2010; Alper, 2007;Özden, 2003). Öğretmen, topluma ve toplumda yaşayan her bireye 1şı tutan, yol gösteren ve rehber olan kişidir. Aynı zamanda bireyin kendisini doğru bir şekilde ifade etmesini sağlayan iletişim kaynağıdır. Bu kaynak, birey için gelecekte olmak ve icra etmek istediği mesleğine olumlu-olumsuz katkılar sağlamaktadır. Yani birey öğretmeninden, ailesinden ve ya yakın çevresindeki birçok bireyden öğrendiği iletişim becerilerini icra edeceği mesleğinde kullanmaktadır. Bu konuda gerek ulusal gerekse uluslararası çalışmalarda (Aksungur, 2018; Ulukan, 2017;Öztemel, 2016; Temiz, 2014; Ün, 2014; Leibowitz, Ramos-Marcuse ve Arsenio, 2002; Balc1 ve Y1lmaz, 1999; Kloth, Janssen, Kraaimaat ve Brutten 1998) iletişimin bireyin sahip olduğu mesleki becerisine çok önemli katkılar sağladığı vurgulanmaktadır. Çalışmalar çoğunlukta nicel olarak yapılmış ve anket-ölçeklerle iletişim becerileri ortaya konulmaya çalışılmıştır. Buna karşın hizmet öncesinde bireylerin gelecek mesleklerinde sahip olacakları iletişim becerilerine yönelik çok az nitel çalışma bulunmaktadır. Bu araştırmada farklı bölümdeki lisans öğrencilerinin iletişim kavramına yönelik algıları metaforik olarak ortaya konulmaya çalışılmıştır.

\section{YÖNTEM}

\section{Araştırma deseni}

$\mathrm{Bu}$ araştırmada nitel araştırma yöntemlerinden “olgu bilim’ kullanılmıştır. Olgu Bilim; İnsanların yaşadığı çevrede farkında olup derinlemesine bir anlayışa sahip olunmayan olgulara odaklanmaktır ( Yıldırım ve Şimşek, 2013). İnsanların yaşadığı cevrede birçok problem, tecrübe ve algılarla karşı karşıya gelmektedir. İnsanların bellekleri yaşadığı çevrede bu uyarıcıların hepsini kaydetmemektedir. Olgu bilim insanların farkındalık düzeyinin belirlenmesinde etkili bir yöntemdir.

\section{Çalışma grubu}

Araştırmanın çalışma grubunu, Siirt Üniversitesinde öğrenim gören İktisadi ve İdari Bilimler, Fen Edebiyat, Eğitim, İlâhiyat, Veterinerlik Fakültesi, Beden Eğitimi ve Spor Yüksek Okulu, Sağlik Yüksekokulu, Yabancı Diller Yüksekokulu, Mühendislik Fakültesi bölümünde öğrenim gören ve gönüllük esasına göre belirlenen 340 lisans öğrencisi oluşturmaktadır.

Araştırmada, çalışma grubunun "iletişim" kavramına yönelik ürettikleri metaforların fakülte ve yüksekokula göre dă̆ılımı Tablo 1'de yer almaktadır.

Tablo 1.

Üniversite öğrencilerinin iletişim kavramına yönelik ürettiği metaforların fakülte ve yüksekokula göre dă̆ılımı

\begin{tabular}{lccc}
\hline \multicolumn{1}{c}{ Bölümler } & Kiz & Erkek & Toplam \\
\hline İktisadi ve İdari Bilimler Fakültesi & 5 & 4 & 9 \\
\hline Fen Edebiyat Fakültesi & 13 & 10 & 23 \\
\hline Eğitim Fakültesi & 110 & 75 & 185 \\
\hline İlahiyat Fakültesi & 16 & 20 & 36 \\
\hline Veterinerlik & 8 & 5 & 13 \\
\hline Beden Eğitimi ve Spor Yüksek Okulu & 7 & 2 & 9 \\
\hline Sağlık Yüksek Okulu & 6 & 4 & 10 \\
\hline Yabancı Diller Yüksekokulu & 18 & 6 & 24 \\
\hline Mühendislik Fakültesi & 2 & 9 & 320 \\
\hline TOPLAM & & &
\end{tabular}

\section{Veri toplamast}

Araştırma verileri, açık uçlu soruların yer aldığı formlar aracılığı ile toplanmıştır. Bu kapsamda araştırmaya katılan öğrencilerin "iletişim” kavramına ilişkin algılarını belirlemek amacıyla açık uçlu bir anket formu hazırlanmıştır. Anket formunda "iletişim........ gibidir; çünkü........." cümlesini tamamlamaları istenmiştir. Çalışma grubundaki öğrencilere araştırmacılar tarafından yalnızca bir metafor üzerine yoğunlaşmaları ve bu metaforun gerekçeleriyle yazmaları konusunda bilgilendirici açıklamalar yapılmıştır. Araştırmacılar çalışmanın sağlıklı yürüyebilmesi için çalışma grubuna birkaç örnek vermiştir. Çalışma grubunun düşüncelerini aktarması için otuz dakikalık bir süre tanınmıştır. Katılımcılar bu sürenin tamamını kullanmayarak 
ilk on dakika içerisinde formu teslim etmişlerdir. İktisadi ve İdari Bilimler, Fen Edebiyat, Eğitim, İlâhiyat, Veterinerlik Fakültesi, Beden Eğitimi ve Spor Yüksek Okulu, Sağlık Yüksekokulu, Yabancı Diller Yüksekokulu ve Mühendislik Fakültesi bölümünde öğrenim gören 340 lisans öğrencisinin doldurduğu formlar, birer belge ve doküman olarak bu çalışmanın temel veri kaynağını oluşturmaktadır.

\section{Verilerin analizi}

Çalışma sonunda elde edilen veriler üzerinden betimsel ve içerik analizi yapılmıştır. Betimsel analizde, veri toplama araçlarından elde edilen veriler önceden belirlenen temalara göre özetlenir ve yorumlanır (Yıldırım ve Şimşek, 2003). Yorumlar yapılırken, bu verilerden alıntılar yapılmaktadır. Bu araştırmada da betimsel analiz çerçevesinde verilerin ilk önce ana çerçevesi belirlenmiştir. Burada amaç verilerin hangi? Temalar altında toplanacağına karar vermektir. Verilerin hangi temalar altında düzenleneceği ve sunulacağı belirlendikten sonra, araştırmacılar tarafından daha önce oluşturulan çerçeveye dayalı olarak veriler okunmuş ve düzenlenmiştir. Sonra araştırmacılar, düzenledikleri verileri tanımlamışlardır. Bunun için de doğrudan alıntılara yer verilmiştir. Doğrudan alıntılar yapılırken öğrencilerin isimleri yerine okudukları bölümlere ilişkin kodlamalar kullanılmıştır (örnek: sağlık yüksekokulu için $\mathrm{S}_{\text {ağlık4 }}, \mathrm{S}_{\text {ağlık.. }}$; Mühendislik için $\mathrm{M}_{\text {ühendislik11 }}, \mathrm{M}_{\text {ühendislik...gibi). }}$

İçerik analizinde temel amaç, toplanan verileri açılayabilen kavramlara ve ilişkilere ulaşmaktır. $\mathrm{Bu}$ amaçla toplanan verilerin önce kavramsallaştırılması daha sonrada ortaya çıkan kavramlara göre mantıklı bir biçimde organize edilmesi ve buna göre veriyi açıklayan temaları saptanması gerekmektedir (Yıldırım ve Şimşek, 2013 ).

Araştırmada ulaşılan yirmi kavramsal kategori altında verilen metaforların, söz konusu bir kavramsal kategoriyi temsil edip etmediğini belirlemek amacıyla uzman görüşüne başvurulmuştur. Uzmanlara iki liste verilmiş ve birinci listede 133 metaforun alfabetik listeye göre dizilmiş hali, ikinci listede ise yirmi farklı kavramsal kategorinin adlarını ve özellikleri yer almaktadır. Uzmandan bu iki listeyi de kullanarak birinci listedeki örnek metafor listesini, ikinci listedeki yirmi kavramsal kategoriyle eşleştirmişlerdir. Daha sonra, uzmanın yaptığı eşleştirmeler araştırmacıların kendi kategorileriyle karşılaştırılmıştır. Karşlaştırmalarda görüş birliği ve görüş̧ ayrılığı sayıları tespit edilerek araştırmanın güvenirliği, Miles ve Huberman'ın (1994: 64) formülü "Güvenilirlik= (Görüş Birliği):(Görüş Birliği+Görüş Ayrılığl)x 100" kullanılarak hesaplanmıştır. Nitel çalışmalarda, uzman ve araştırmacı değerlendirmeleri arasındaki uyumun 0.93 ve üzeri olduğu durumlarda istenilen düzeyde bir güvenilirlik sağlanmış olmaktadır (Saban, 2009).

\section{BULGULAR}

Bu bölümde elde edilen veriler tablolar halinde verilmiştir.

\section{İletişim kavramina yönelik metaforlar}

Araştırmada, 320 metafordan; 42 kişi (Su, Rüzgar, sevgi, damar, tablo, aşk,) 42 kişi (insan, telefon, yağmur, anlaşma, araç, mutluluk, sevgi, düşünce), 36 kişi ( göz, çiçek, yol, kuş, anne, dağ, araba, ağaç, yaşam, ayna, alışveriş, doğa), 26 kişi (sosyal medya, yağmur, güven, arkadaş, çocuk, dalga, felsefe, müzik, sevgili, ş̧ı, kalem, bebek, empati), 36 kişi (birey puzzle, bağ, güneş, aile, okyanus, sınav, ulaşım ağı, muhabbet, oyun, kadın, ihtiyaç, gökyüzü, dil, elektrik tel, tebessüm, televizyon, nehir), 9 kişi (ilk konuşma, ömür, sorumluluk, facebook, duygu, anlama) metaforunu üretmiştir. Üretilen metaforlar ve bu metaforların frekansları Tablo 2'de gösterilmiştir.

Tablo 2 .

Öğrencilerinin iletişim kavramına yönelik ürettikleri metaforların frekans tablosu

\begin{tabular}{cccccc}
\hline Metafor Kodu & Metafor Adı & f & Metafor Kodu & Metafor Adı & f \\
\hline $\mathbf{1 .}$ & Su & 9 & $\mathbf{9 .}$ & Kuş & 3 \\
\hline $\mathbf{2 .}$ & Rüzgar & 8 & $\mathbf{1 0 .}$ & Anne & 3 \\
\hline $\mathbf{3 .}$ & Sevgi & 7 & $\mathbf{1 1 .}$ & Dağ & 3 \\
\hline $\mathbf{4 .}$ & Kablo & 6 & $\mathbf{1 2 .}$ & Araba & 3 \\
\hline $\mathbf{5 .}$ & Damar & 6 & $\mathbf{1 3 .}$ & Ağaç & 3 \\
\hline $\mathbf{6 .}$ & Aşk & 6 & $\mathbf{1 4 .}$ & Yaşam & 3 \\
\hline $\mathbf{7 .}$ & Oksijen & 5 & $\mathbf{1 5 .}$ & Ayna & 3 \\
\hline $\mathbf{8 .}$ & Hava / Kar & 5 & $\mathbf{1 6 .}$ & Alışveriş & 3 \\
\hline
\end{tabular}


Tablo 2. (Devamı)

\begin{tabular}{|c|c|c|c|c|c|}
\hline Metafor Kodu & Metafor Adı & $\mathbf{f}$ & Metafor Kodu & Metafor Adı & $\mathbf{f}$ \\
\hline 17. & İnsan & 4 & 70. & Doğa & 3 \\
\hline 18. & Telefon & 4 & 71. & Bebek & 2 \\
\hline 19. & Yağmur & 4 & 72. & Kalem & 2 \\
\hline 20. & Araç & 4 & 73. & Iş1k & 2 \\
\hline 21. & Mutluluk & 4 & 74. & Sevgili & 2 \\
\hline 22. & Sevgi & 4 & 75. & Müzik & 2 \\
\hline 23. & Düşünce & 4 & 76. & Dalga & 2 \\
\hline 24. & Telefon & 4 & 77. & Anlaşma & 2 \\
\hline 25. & Göz & 3 & 78. & Çocuk & 2 \\
\hline 26. & Yol & 3 & 79. & Arkadaş & 2 \\
\hline 27. & Güven & 2 & 80. & Buluşma & 2 \\
\hline 28. & Sosyal Medya & 2 & 81. & Mavi & 2 \\
\hline 29. & Empati & 2 & 82. & Allah & 2 \\
\hline 30. & Televizyon & 2 & 83. & Duman & 2 \\
\hline 31. & Tebessüm & 2 & 84. & Yank1 & 2 \\
\hline 33. & Elektrik Teli & 2 & 85. & İp & 2 \\
\hline 34. & Dil & 2 & 86. & Kumanda & 2 \\
\hline 35. & Gökyüzü & 2 & 87. & Zincir halkası & 2 \\
\hline 36. & İhtiyaç & 2 & 88. & Ölçü & 2 \\
\hline 37. & Kadın & 2 & 89. & Kap1 kolu & 2 \\
\hline 38. & Oyun & 2 & 90. & Yemek & 2 \\
\hline 39. & Muhabbet & 2 & 91. & Huzur & 2 \\
\hline 40. & Ulaşım Ağ1 & 2 & 92. & Motor yağ 1 & 2 \\
\hline 41. & Sinav & 2 & 93. & Sanat & 2 \\
\hline 42. & Okyanus & 2 & 94. & Iş1k & 2 \\
\hline 43. & Aile & 2 & 95. & Hastalık & 2 \\
\hline 44. & Güneş & 2 & 96. & Ak1l & 2 \\
\hline 45. & Puzzle & 2 & 97. & Kahvaltı & 2 \\
\hline 46. & Birey & 2 & 98. & Işınlanma & 2 \\
\hline 47. & Ömür & 2 & 99. & Karınca & 2 \\
\hline 48. & İlk konuşma & 2 & 100. & Ahtapot & 2 \\
\hline 49. & Sorumluluk & 2 & 101. & Twiter & 2 \\
\hline 50. & Bahar & 2 & 102. & Toplum & 2 \\
\hline 51. & Fotosentez & 2 & 103. & Duvar & 2 \\
\hline 52. & Sembol & 2 & 104. & Facebook & 1 \\
\hline 52. & Fakülte & 2 & 105. & Duygu & 1 \\
\hline 54. & Pasta & 2 & 106. & Anlama & 1 \\
\hline 55. & Sağlık & 2 & 107. & Güvercin & 1 \\
\hline 56. & Pencere & 2 & 108. & Ekmek & 1 \\
\hline 57. & Etki & 2 & 109. & Şeytan & 1 \\
\hline 58. & Eğitim & 2 & 110. & Elektrik & 1 \\
\hline 59. & Nehir & 2 & 111. & Sigara & 1 \\
\hline 60. & Bulut & 2 & 112. & Dolaşım sistemi & 1 \\
\hline 61. & Kule & 2 & 113. & Çikolata & 1 \\
\hline 62. & Makyaj Bazı & 2 & 114. & Tatli & 1 \\
\hline 63. & Demlik & 2 & 115. & Bilgisayar & 1 \\
\hline 64. & Gülen yüz & 2 & 116. & Nikotin & 1 \\
\hline 65. & Bağ & 2 & 117. & Seratonin & 1 \\
\hline 66. & Evlat & 2 & 118. & Gece gündüz & 1 \\
\hline 67. & Teslis inanc1 & 2 & 119. & Anahtar & 1 \\
\hline 68. & Üslup & 2 & 120. & Çeyiz & 1 \\
\hline 69. & Çizgi film & 2 & 121. & Evren & 1 \\
\hline
\end{tabular}


Tablo 2. (Devami)

\begin{tabular}{|c|c|c|c|c|c|}
\hline Metafor Kodu & Metafor Adı & f & Metafor Kodu & Metafor Adı & $\mathbf{f}$ \\
\hline 122. & Limit & 1 & 137. & Fotoğraf & 1 \\
\hline 123. & Matematik & 1 & 138. & Uyku & 1 \\
\hline 124. & Köprü & 1 & 139. & Satranç & 1 \\
\hline 125. & İlişkinin temeli & 1 & 140. & Giybet & 1 \\
\hline 126. & $\mathrm{Ev}$ & 1 & 141. & Çay & 1 \\
\hline 127. & Süreklilik & 1 & 142. & Örümcek ağ1 & 1 \\
\hline 128. & Uçak hızı & 1 & 143. & Dost & 1 \\
\hline 129. & Jest-mimik & 1 & 144. & Dua & 1 \\
\hline 130. & Soba & 1 & 145. & Pilsiz oyuncak & 1 \\
\hline 131. & Petek & 1 & 146. & Ses telleri & 1 \\
\hline 132. & İnternet & 1 & 147. & Tren & 1 \\
\hline 133. & Tanrı & 1 & 148. & Silah & 1 \\
\hline 134. & Uzay & 1 & 149. & Durak & 1 \\
\hline 135. & Özlem & 1 & 151. & Google & 1 \\
\hline 136. & Davul & 1 & 152. & Bayram & 1 \\
\hline \multicolumn{6}{|c|}{ TOPLAM:320 } \\
\hline
\end{tabular}

\section{İletişim kavramına yönelik üretilen metaforların kategorileri}

Çalışma grubundaki öğrencilerin iletişim kavramına yönelik 320 metafor örneği 20 kategori adı altında sınıflandırılmış ve bunlar Tablo 3'de gösterilmiştir.

Tablo 3.

Üniversite ögrencilerinin iletişim kavramına yönelik ürettikleri metaforların kategorileri

\begin{tabular}{|c|c|c|c|c|}
\hline & Kategori & Metafor & $\mathbf{f}$ & $\begin{array}{c}\text { Metafor } \\
\text { Adedi }\end{array}$ \\
\hline 1. & Temel ihtiyaçlar & Ekmek, su (9), nefes, oksijen (5), uyku (2), tatl1 & 19 & 6 \\
\hline 2. & Doğa olayları & Rüzgar (8), güneş (2), hava (2) dalga (2) & 14 & 4 \\
\hline 3. & Hayvanlar & Kuş (2), ahtapot, Kelebek (2), güvercin & 6 & 4 \\
\hline 4. & Bitkiler & Çiçek (3), ağaç (3) & 6 & 2 \\
\hline 5. & İletişim & $\begin{array}{c}\text { Jest-mimik, ses tonu (2), göz temas1, işaret dili, } \\
\text { sohbet-muhabbet, düşünce, anlaşma(4) }\end{array}$ & 11 & 7 \\
\hline 6. & Parlaklik & Petek, soba, 1ş1k, elektrik, ateş & 5 & 5 \\
\hline 7. & Bilgi kaynağı & $\begin{array}{l}\text { Kitap, bilgisayar, telefon (4), pandora kutusu, } \\
\text { Google, internet, okul, ev, sosyal medya (2) }\end{array}$ & 14 & 10 \\
\hline 8. & Vücudumuz sistemleri & Damarlar (6), dolaşım sistemi & 7 & 2 \\
\hline 9. & Derinlik & Çukur, deniz, okyanus (2), felsefe & 5 & 4 \\
\hline 10. & Karşılıklı & Alışveriş (3), ayna (2) & 5 & 2 \\
\hline 11. & Coğrafya & Gece, gündüz, evren & 2 & 2 \\
\hline 12. & Duyuşsal boyut & Mutluluk (3), aile(2),Arkadaş (2) & 7 & 3 \\
\hline 13. & Uzunluk & Kablo (6), telefon şarj1, köprü, yol (2) & 10 & 4 \\
\hline 14. & Kötü & Şeytan, sigara, silah & 3 & 3 \\
\hline 15. & Süreklilik sağlaması & Üreme, limit & 2 & 2 \\
\hline & Bütünleyici & Puzzle/ yapboz (3), edat/bağlaç & 4 & 2 \\
\hline & Ahenk içinde olması & Müzik & 1 & 1 \\
\hline & Sonsuz olması & Aşk (6), uzay, ruh & 8 & 3 \\
\hline & Ulaşılması gereken yer & Kilit & 1 & 1 \\
\hline & Taşitlar & Araba (2), tren & 3 & 2 \\
\hline
\end{tabular}


Tablo 3'de görüldüğü üzere iletişim kavramına yönelik 20 temel kategori bulunmaktadır. Bu kategoriler aşağıda başlıklar halinde ele alınmış ve kategorilere ilişkin öğrenci görüşlerinde doğrudan alıntılara yer verilmiştir.

Kategori 1: Temel İhtiyaçlar

Bu kategoriyi oluşturan 6 metaforu, 19 öğrenci üretmiştir. Bunlar; “ekmek “,”su “, ”nefes“, “ oksijen “, " uyku "ve " tatlı "dır. Bu kategoriyi oluşturan katılımcıların ifadeleri şu şekildedir.

“İletişim ekmeğe benzer; Çünkü iletişim gibi olmazsa olmaz .” $\left(\mathrm{S}_{\text {ağlık1 }}\right)$

"İletişim suya benzer; Çünkü girdiği bardağın şeklini alır, iletişimde kişide şekil alır.”(Y $\left.{ }_{\text {Dil3 }}\right)$

"İletişim suya benzer; Çünkü insan susuzda iletişimsizde yaşayamaz." ( $\left.\mathrm{M}_{\text {ühendislik3 }}\right)$

“İletişim suya benzer; Çünkü düşüncelerde su gibi akar bazen durgun bazen şiddetlidir.”( $F_{\text {Edebiyat5) }}$

"İletişim suya benzer; Çünkü iletişimde su gibi yaşama sebebidir." ( $\left.Y_{\text {Dils }}\right)$

"İletişim suya benzer; Çünkü su ve iletişim insanların vazgeçilmezidir." (E ğgitim55 $_{\text {) }}$

"İletişim suya benzer; Çünkü su ve iletişim hayatın olmazsa olmazıdır.”( $\left.E_{\text {ğitim5 }}\right)$

"İletişim suya benzer; Çünkü ne susuz ne de iletişimsiz yaşayabilir.” (F $F_{\text {Edebiyat15 }}$ )

“İletişim suya benzer; Çünkü su aktıkça yolunu bulur, iletişimde yapılırsa huzur verir.” (E ğitim87)

"İletişim suya benzer; Çünkü susuz hayat uzun sürmez iletişimsiz de öyle." ( $\left.\dot{\mathrm{I}}_{\text {Idari 1 }}\right)$

"İletişim oksijene benzer; Çünkü oksijen olmadan ve iletişim olmadan insan bir hiç.” (E $\left.\mathrm{E}_{\text {ğitim115 }}\right)$

"İletişim oksijene benzer; Çünkü oksijen gibi iletişimde şarttır.” $\left(\mathrm{S}_{\text {ağlık4 }}\right)$

"İletişim oksijene benzer; Çünkü oksijen olmadan insan nefes alamaz iletişimsiz de insanlar yaşayamaz." $\left(\mathrm{E}_{\text {ğitim118 }}\right)$

"İletişim oksijene benzer; Çünkü iletişimde insan hayatı için şarttır." (Ĕğitim123)

"İletişim oksijene benzer; Çünkü hem iletişim hem oksijen olmazsa olmazdır." (' $\left.\dot{\mathrm{I}}_{\text {lahiyat21 }}\right)$

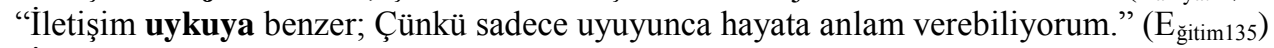

"İletişim uykuya benzer; Çünkü huzur veriyor." ( $\left.\mathrm{V}_{\text {ternerlik1 }}\right)$

"İletişim tatlıya benzer; Çünkü onun gibi bağımlılık yapıyor.” ( E ğitim145 $_{\text {. }}$

"İletişim nefese benzer; Çünkü nefes gibi onu alıp yeri geldiğinde bırakmalıyız.” $\left(\mathrm{B}_{\mathrm{den} 5}\right)$

Kategori 2 : Doğa Olayları

$\mathrm{Bu}$ kategoriyi oluşturan 4 metaforu 14 öğrenci üretmiştir. Bunlar; "rüzgar”, "güneş”, "hava" ve “dalga"dır. Bu kategoriyi oluşturan katılımcı ifadeleri şu şekildedir.

“ İletişim rüzgara benzer; Çünkü elle tutulmaz ama hissedersin.” $\left(\mathrm{S}_{\text {ağık } 8}\right)$

"İletişim rüzgara benzer; Çünkü her yerde varlığını hissettir." ( $\left.\mathrm{V}_{\text {ternerlik10 }}\right)$

"İletişim rüzgara benzer; Çünkü her yere ulaşır. " $\left(\mathrm{Y}_{\text {Dil20 }}\right)$

"İletişim rüzgara benzer; Çünkü her zaman hissederiz. " $\left(\mathrm{E}_{\breve{g ̆ i t i m} 19}\right)$

"İletişim rüzgara benzer; Çünkü her yere esip ulaşır. " $\left(\dot{\mathrm{I}}_{\text {lahiyat25 }}\right)$

"İletişim rüzgara benzer; Çünkü her yere eser. " $\left(\mathrm{F}_{\text {Edebiyat21 }}\right)$

"İletişim rüzgara benzer; Çünkü görmesek bile var olduğunu biliriz. “( $\left.\mathrm{B}_{\mathrm{den} 9}\right)$

"İletişim rüzgara benzer; Çünkü her yere bizimle gelir. “ $\left(\mathrm{M}_{\text {ühendislik11 }}\right)$

"İletişim güneşe benzer; Çünkü fazlası yakar az oldu mu soğutur. (Böt1)

"İletişim güneşe benzer; Çünkü hayatımıza sıcaklık aydınlık kazandırır. "( $\left.\mathrm{S}_{\text {ağık5 }}\right)$

"İletişim havaya benzer; Çünkü havada iletişim gibi her yerde var.” (İं̇ari6)

"İletişim havaya benzer; Çünkü iletişimde hava gibi görülmez ama vardır. "( Eğitim116 $\left._{16}\right)$

"İletişim dalgaya benzer; Çünkü onun gibi bazen durgun bazen serttir. "( $\left.\mathrm{F}_{\text {Edebiyat23 }}\right)$

"İletişim dalgaya benzer; Çünkü dalgada etkileyicidir. "( $\left(\mathrm{E}_{\text {ğitim184 }}\right)$

Kategori 3: Hayvanlar

$\mathrm{Bu}$ kategoriyi oluşturan 4 metaforu 6 öğrenci üretmiştir. Bunlar; "kuş“", "kelebek", "ahtapot" ve "güvercin"dir. Bu kategoriyi oluşturan katılımcı ifadeleri şu şekildedir.

“İletişim kuşa benzer; Çünkü kuşta sürekli öter bir şeyler anlatır. “( $\left.E_{\text {ğitim10 }}\right)$

"İletişim kuşa benzer; Çünkü iletişimde kuş gibi her yere ulaşır. " $\left(\mathrm{V}_{\text {ternerlik6}}\right)$

"İletişim ahtapota benzer; Çünkü iletişim gibi bir sürü kolu vardır. " $\left(\mathrm{V}_{\text {ternerlik8})}\right.$

"İletişim güvercine benzer; Çünkü istediği yere uçar ve ulaşır. “( $\left.E_{\breve{g ̆ i t i m} 88}\right)$ 
“İletişim kelebeğe benzer; Çünkü onun gibi narin ve güzeldir. “( $\left.\mathrm{S}_{\mathrm{ağl} l k 3}\right)$

"İletişim kelebeğe benzer; Çünkü iletişim gibi kanatları var. " $\left(F_{\text {Edebiyat11 }}\right)$

\section{Kategori 4: Bitkiler}

Bu kategoriyi oluşturan 2 metaforu 6 öğrenci üretmiştir. Bunlar; "ağaç" ve "çiçek”dir. Bu kategoriyi oluşturan katılımcı ifadeleri aşağıda verilmiştir.

“İletişim ağaca benzer; Çünkü iletişiminde ağaç gibi birden fazla kolu vardır. "( $\left(Y_{\text {Dills }}\right)$

"İletişim ağaca benzer; Çünkü ağaca su verirsek meyve verir, insanla iletişime geçersek dönüt alırız. " $\left(\mathrm{V}_{\text {ternerlik12 }}\right)$

"İletişim ağaca benzer; Çünkü her kolunda iletişim gibi kaynak bulundurur. " $\left(\dot{I}_{\text {lahiyat7 }}\right)$

"İletişim çiçeğe benzer; Çünkü insana huzur verir. "( $\left(\mathrm{B}_{\mathrm{den} 3}\right)$

"İletişim çiçeğe benzer; Çünkü yavaş yavaş açılır ve keşfedersin. " $\left(\mathrm{S}_{\mathrm{ağl} l k 1}\right)$

"İletişim çiçeğe benzer; Çünkü topladıkça mutlu olursun iletişime geçince de mutlu olursun. “( $\left.\mathrm{E}_{\breve{g} \text { itim178 }}\right)$

Kategori 5: İletişim

Bu kategoriyi oluşturan 7 metaforu 9 öğrenci üretmiştir. Bunlar; "Jest-mimik”, "sohbet -muhabbet “, "ses tonu”, "göz teması", "işaret dili”, "düşünce "ve "anlaşma"dır. Bu kategoriyi oluşturan katılımcı ifadeleri aşağıda verilmiştir.

“İletişim jest mimiklere benzer; Çünkü dilden sonra kendimizi en iyi ifade ettiğimiz şekildir.” (E Ĕitim14)

"İletişim ses tonuna benzer; Çünkü insani iletişimde ilk etkileyendir." $\left(\mathrm{S}_{\text {ağık6 }}\right)$

"İletişim göz temasına benzer; Çünkü iletişimde en etkilenilen. "( $\left(\mathrm{M}_{\text {ühendislik7 }}\right)$

"İletişim işaret diline benzer; Çünkü sözle olmasa da iletişimi sağlama şeklidir. ”( $\left.Y_{\text {Dil20 }}\right)$

"İletişim ses tonuna benzer; Çünkü ruh halini ifade eder. " $\left(\mathrm{F}_{\text {Edebiyat21 }}\right)$

"İletişim anlaşmaya benzer; Çünkü karşılıklı bir alışveriştir. " $\left(\mathrm{B}_{\mathrm{den} 9}\right)$

"İletişim anlaşmaya benzer; Çünkü anlaştığın kişiyle iletişim kurarsın. "(E Ĕgitim15 $)$

"İletişim düşünceye benzer; Çünkü kendi düşüncelerini karşındakine ne anlatıp, karşıdakinin de sana anlatmasıdır. "( $\left.\dot{\mathrm{I}}_{\text {Idari } 7}\right)$

"İletişim sohbet-muhabbete benzer; Çünkü karş1lıklı yapılan bir etkileşim vardır. "( $\left.\mathrm{V}_{\text {ternerlik13 }}\right)$

Kategori 6: Parlaklık

Bu kategoriyi oluşturan 5 metaforu 5 öğrenci üretmiştir. Bunlar; "Petek”, ,'Soba" , "Işık” , "Elektrik” ve “Ateş “dir. Bu kategoriyi oluşturan ifadeler şu şekildedir.

“İletişim peteğe benzer; çünkü etrafa sıcaklık verir.” ( $\left.\mathrm{E}_{\breve{g ̆ i t i m 12}}\right)$

"İletişim sobaya benzer; Çünkü etrafına ısı verir." ( $\left.\mathrm{M}_{\text {ühendislik4 }}\right)$

"İletişim ışığa benzer; Çünkü aydınlatır her yeri." ( $\left.\mathrm{B}_{\mathrm{den} 6}\right)$

"İletişim elektriğe benzer; Çünkü herkesi kendine çeker." ( $\left.\dot{\mathrm{I}}_{\text {lahiyat2 }}\right)$

“İletişim ateşe benzer çok yakın olursa yanarsın çok uzak olursa üşürsün.” ( $\left.\mathrm{V}_{\text {ternerlik8}}\right)$

Kategori 7: Bilgi Kaynağ1

Bu kategoriyi oluşturan 10 metaforu 14 öğrenci üretmiştir. Bunlar; "Kitap", "Bilgisayar” , "Telefon” , "Pandora kutusu", "Google”, "İnternet" , "Ev" , "Okul” , "Facebook” ve ”Sosyal medya"dır. Bu kategoriyi oluşturan ifadeler şu şekildedir.

“İletişim kitaba benzer; Çünkü her kitapta insana kazandırılacak bilgiler vardır.” (Eğitim37)

"İletişim bilgisayara benzer; Çünkü içinde bir sürü bilgi var.” (E $\left.\mathrm{E}_{\text {ğitim41 }}\right)$

"İletişim telefona benzer; Çünkü her yere ulaşır." ( $\dot{\mathrm{I}}_{\text {lahiyat23 }}$ )

"İletişim telefona benzer; Çünkü içinde her bilgi vardır." ( $\left.\dot{\mathrm{I}}_{\text {lahiyat30}}\right)$

"İletişim telefona benzer; Çünkü çoğu iletişimin en önemli kaynağı telefondur.” ( $\left.M_{\text {ühendislik5 }}\right)$

“İletişim telefona benzer; Çünkü içindeki bilgilere bazen ulaşması kolay bazen de zordur.” ( $\left.\mathrm{M}_{\text {ühendislik7 }}\right)$

"İletişim Pandora kutusuna benzer; Çünkü içinden ne çıkacağı belli değildir."

"İletişim Google benzer; Çünkü içinde her türlü bilgi var derine indikçe bilgilere ulaşırsın.” ( $\left.\mathrm{M}_{\text {ühendislik8 }}\right)$

"İletişim internete benzer; Çünkü kısa bir süreliğine girmek istersin saatlerce içinden çıkamazsın.” (B $\left.B_{\text {den8 }}\right)$

"İletişim eve benzer; çünkü ilk iletişim ailede başlar." (İं̇aris)

"İletişim okula benzer; Çünkü iletişimin etkili olmasını sağlayan en önemli yer okuldur.” ( $\left.\mathrm{V}_{\text {ternerlik9 }}\right)$

"İletişim Facebook a benzer; Çünkü Facebook olmazsa iletişimin bir parçası eksilir." (Y Dil12)

“İletişim sosyal medyaya benzer; Çünkü genel olarak iletişim sosyal medya ile sağlanıyor.” $\left(\mathrm{S}_{\mathrm{ağl} l k 10}\right)$

"İletişim sosyal medyaya benzer; Çünkü iletişimin yapı taşıdır." (Febiyat19) 
Kategori 8: Vücudumuzun Sistemleri

Bu kategoriyi oluşturan 2 metaforu 7 öğrenci üretmiştir. Bunlar; "Damarlar" ve "Dolaşım sistemi"dir.

$\mathrm{Bu}$ kategoriyi oluşturan ifadeler şu şekildedir.

"iletişim damara benzer; Çünkü bütün damarlar iletişim gibi birbiri ile bağlantılıdır." $\left(\mathrm{S}_{\text {ă̆lık }}\right)$

"İletişim damara benzer; Çünkü vücudumuzdan bir parçadır ve her zaman bizimledir." ( $\left.\mathrm{V}_{\text {ternerlik8 }}\right)$

"İletişim damara benzer; Çünkü iletişim gibi her yerimizi sarmış vaziyette." $\left(\mathrm{S}_{\mathrm{ağl} ı k}\right)$

"İletişim damara benzer; Çünkü damarlarda iletişim gibi her yere uzanır." $\left(\mathrm{B}_{\mathrm{den} 7}\right)$

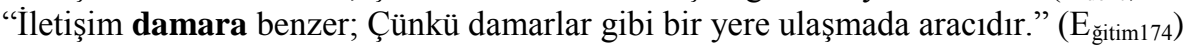

"İletişim damara benzer; Çünkü iletişim gibi damarlarda birbirine bağlı şekildedir.” ( $\left.\mathrm{F}_{\text {Edebiyat2 }}\right)$

"İletişim dolaşım sistemine benzer; Çünkü her an her yerde bizimledir iletişimimizi sağlar." $\left(\mathrm{M}_{\text {ühendislik6 }}\right)$

Kategori 9: Derinlik

Bu kategoriyi oluşturan 4 metaforu 5 öğrenci üretmiştir. Bunlar; "Çukur”, "Deniz", "Okyanus” ve “ Felsefe"dir. Bu kategoriyi oluşturan ifadeler şu şekildedir.

"İletişim çukura benzer; Çünkü çukur gibi bir derinliği vardır." ( $\left(M_{\text {ühendislik2 }}\right)$

"İletişim denize benzer; Çünkü deniz kadar içinde bilgi vardır." ( $\mathrm{F}_{\text {Edebiyat19) }}$

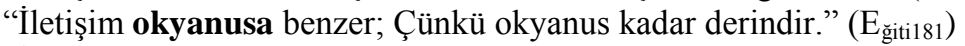

"İletişim okyanusa benzer; Çünkü derine indikçe bir şeyler keşfedersin.” $\left(\mathrm{E}_{\breve{g ̆ t i m}} 183\right)$

"İletişim felsefeye benzer; Çünkü içeriği derin ve herkes ulaşamaz." ( $\left.\mathrm{F}_{\text {Edebiyat20 }}\right)$

Kategori 10: Karşıllklı

Bu kategoriyi oluşturan 2 metaforu 5 öğrenci üretmiştir. Bunlar; "Alı̧sveriş" ve "Ayna" dır. Bu kategoriyi oluşturan ifadeler şu şekildedir.

"İletişim alışverişe benzer; Çünkü iletişim iki kişi ile karşılıklı olur." $\left(\mathrm{S}_{\text {ağılk8 }}\right)$

"İletişim alışverişe benzer; Çünkü çoğu kişiye haz verir." ( $\mathrm{E}_{\text {ğtim116 }}$ )

"İletişim alı̧̧verişe benzer; Çünkü karş1lıklı bilgi, düşünce olur.” $\left(\mathrm{Y}_{\mathrm{Di} 20}\right)$

"İletişim aynaya benzer; Çünkü karşındaki ile ne şekilde iletişime geçersen o şekilde sana yansır."

"İletişim aynaya benzer; Çünkü her insanın iletişimi kendisini yansıtır." ( $\dot{\mathrm{I}}_{\text {lahiyat25 }}$ )

Kategori 11: Coğrafya

Bu kategoriyi oluşturan 2 metaforu 2 öğrenci üretmiştir. Bunlar; "Gece-gündüz" ve "Evren"dir. Bu kategoriyi oluşturan ifadeler şu şekildedir.

"İletişim gece-gündüze benzer; Çünkü gece gündüzü tamamlar dilde iletişimi tamamlar." ( $E_{\text {ğitim165 }}$ )

"İletişim evrene benzer; Çünkü hem iletişimin hem de evrenin belli bir düzeni vardır.” $\left(F_{\text {Edebiyat9 }}\right)$

Kategori 12: Duyuşsal Boyut

Bu kategoriyi oluşturan 3 metaforu 7 öğrenci üretmiştir. Bunlar; "Mutluluk", "Aile" ve "Arkadaş"dır. $\mathrm{Bu}$ kategoriyi oluşturan ifadeler şu şekildedir.

"İletişim mutluluğa benzer; Çünkü mutlu olunca nasıl huzurlu oluyorsan iletişim kurunca da öyle huzurlu olursun." ( $\left.\mathrm{F}_{\text {Edebiyat11 }}\right)$

"İletişim mutluluğa benzer; Çünkü iletişim karş̧1lkklı olunca mutlu olunur." "( $\left.\mathrm{E}_{\text {ğtim3}}\right)$

"İletişim mutluluğa benzer; Çünkü doğru iletişim kurunca mutlu olabiliriz. " $\left(\mathrm{S}_{\text {ağılk1 }}\right)$

"iletişim aileye benzer; Çünkü ailede iletişim gibi yokluğu hissedilir. " $\left(\dot{I}_{\text {lahiyat2 }}\right)$

"İletişim aileye benzer; Çünkü bazen yanında olmasa bile varlığını bilmen yetiyor." $\left(B_{\text {den7 }}\right)$

"Illetişim arkadaşa benzer; Çünkü bazen gerekli bazen gereksiz." $\left(\mathrm{V}_{\text {ternerlik11 }}\right)$

"İletişim arkadaşa benzer; Çünkü var olunca bırakırsın olmayınca sıkılırsın.” " $\left(\mathrm{E}_{\breve{g ̆ t i t i m} 18)}\right.$

Kategori 13: Uzunluk

Bu kategoriyi oluşturan 4 metaforu 10 öğrenci üretmiştir. Bunlar; "Kablo", "Telefon şarjı", "Köprü” ve

"Yol"dur. Bu kategoriyi oluşturan ifadeler şu şekildedir.

"İletişim kabloya benzer; Çünkü oda iletişim gibi etkileşimi sağlar." $\left(\mathrm{V}_{\text {ternerliks }}\right)$

"İletişim kabloya benzer; Çünkü aradaki bağlantıyı sağlar." ( $\left.\mathrm{F}_{\text {Edebiyats }}\right)$

"İletişim kabloya benzer; Çünkü kablo gibi her yere uzanır. "(İ $\left.\dot{I}_{\text {idarig }}\right)$

"İletişim kabloya benzer; Çünkü iki uçlu ve aracı olduğu için." ( $\left.\mathrm{S}_{\text {ağlık } 5}\right)$

"Illetişim kabloya benzer; Çünkü sürekli etkileşim sağlar." ( $\left.\mathrm{Y}_{\text {Dil10 }}\right)$

"İletişim kabloya benzer; Çünkü iletişim gibi kabloda iletişim aracına enerji verir.” "“( $\left.\mathrm{M}_{\text {ühendislik3 }}\right)$ 
"İletişim telefon şarjına benzer; Çünkü telefona enerji verir." " $\left(\mathrm{M}_{\text {ühendislik8 }}\right)$

"İletişim köprüye benzer; Çünkü birbirleri arasındaki bağlantıyı kurar." " $\left(\mathrm{E}_{\text {ğtim11 }}\right)$

"İletişim yola benzer; Çünkü yol çalışması varsa yolculuk iyi geçer. "( $\left.\mathrm{E}_{\text {ğtim150 }}\right)$

"İletişim yola benzer; Çünkü yol hiç bitmez." " $\left(\mathrm{E}_{\text {ğtim176 }}\right)$

\section{Kategori 14: Kötü}

Bu kategoriyi oluşturan 3 metaforu 3 öğrenci üretmiştir. Bunlar; "Şeytan", "Sigara" ve "Silah"dır. Bu kategoriyi oluş̧uran ifadeler şu şekildedir.

"İletişim sigaraya benzer; Çünkü bağımlılık yapıyor. " $\left(\mathrm{S}_{\mathrm{ağ̆lk} 3}\right)$

"İletişim şeytana benzer; Çünkü insanın aklını çeliyor ve iletişim araçlarından vazgeçmez hale geliyorsunuz." $\left(\mathrm{B}_{\mathrm{den} 7}\right)$

"İletişim silaha benzer; Çünkü bazen senin hayatını kaybetmene sebep olabiliyor.” " $\left(E_{\text {ğtitim14 }}\right)$.

Kategori 15: Süreklilik Sağlaması

Bu kategoriyi oluşturan 2 metaforu 2 öğrenci üretmiştir. Bunlar; "üreme", "limit”dir. Bu kategoriyi oluşturan ifadeler şu şekildedir.

“İletişim üremeye benzer; Çünkü sürekli artar çoğalır." $\left(\mathrm{S}_{\mathrm{ağı̆k} k 8}\right)$

"İletişim limite benzer; Çünkü limit gibi süreklilik sağlar.” $\left(\mathrm{V}_{\text {ternerlik5 }}\right)$

Kategori 16: Bütünleyici

Bu kategoriyi oluşturan 2 metaforu 4 öğrenci üretmiştir. Bunlar; "Yapboz - puzzle" ve "Edat Bağlaç'dır. Bu kategoriyi oluşturan ifadeler şu şekildedir.

"İletişim yapboza benzer; Çünkü bir araya gelmedikçe bir anlam ifade etmez." ( $\left.\mathrm{F}_{\text {Edebiyat5 }}\right)$

"İletişim yapboza benzer; Çünkü bir parçası eksik olduğunda iletişim de eksik kalır." (İ ${ }_{\text {Idaris }}$ )

"İletişim yapboza benzer; Çünkü bir bütün oluşturmak için parçalara ihtiyaç vardır. " $\left(\mathrm{M}_{\text {ühendislikg }}\right)$

"İletişim edat-bağlaca benzer; Çünkü cümleye girmedikçe anlam kazanmaz." "( $\left(\mathrm{E}_{\text {ğtim18 }}\right)$

Kategori 17: Ahenk İçinde Olması

Bu kategoriyi oluşturan 1 metaforu 1 öğrenci üretmiştir. Bunlar; “ müzik”dir. Bu kategoriyi oluşturan ifade şu şekildedir.

"İletişim müziğe benzer; Çünkü müzik gibi iletişim de söylemek istediklerine, duygularına tercüme olur." $\left(\mathrm{E}_{\text {ğtim98 }}\right)$.

Kategori 18: Sonsuz Olmas1

Bu kategoriyi oluşturan 3 metaforu 8 öğrenci üretmiştir. Bunlar; "Aşs" , "Uzay" ve "Ruh"dur. Bu kategoriyi oluşturan ifadeler şu şekildedir.

"İletişim aşka benzer; Çünkü hem aşk hem iletişim sonsuzdur." ( $\left.\mathrm{F}_{\text {Edebiyat9 }}\right)$

"İletişim aşka benzer; Çünkü ilerledikçe bağlanırsın kopamaz hale gelirsin." $\left(\mathrm{V}_{\text {ternerlik4 }}\right)$

"İletişim aşka benzer; Çünkü sevdikçe daha çok iletişim olur." $\left(\mathrm{S}_{\mathrm{ağlk}}\right)$

"İletişim aşka benzer; Çünkü iletişim kurarken en mutlu olduğumuz andır. " $\left(\mathrm{Y}_{\mathrm{Dil2}}\right)$

"İletişim aşka benzer; Çünkü ilk aşkın temelini iletişim oluşturur." "( $\left(\mathrm{E}_{\text {ğtim16 }}\right)$

"İletişim aşka benzer; Çünkü aşk olmazsa İnsanlar agresif olur iletişim eksik kalır." "( $\left(\mathrm{M}_{\text {ühendislik6 }}\right)$

"İletişim uzaya benzer; Çünkü hem uzay hem iletişim sonsuzdur."

"İletişim ruha benzer; Çünkü derin ve edebilir. "( $\left.\dot{I}_{\text {lahiyat19 }}\right)$

Kategori 19: Ulaşılması Gereken Yerleri Açma

Bu kategoriyi oluşturan 1 metaforu 1 öğrenci üretmiştir. Bunlar; "Kilit" dir. Bu kategoriyi oluşturan ifade şu şekildedir.

"İletişim kilide benzer; Çünkü doğru iletişim sağlıklı bir biçimde anlaşmayı sağlar. (E $\left.\mathrm{E}_{\breve{g ̆ t i t i m} 6}\right)$

Kategori 20: Taşıtlar

Bu kategoriyi oluşturan 2 metafor 3 öğrenci üretmiştir. Bunlar; "Araba" ve "Tren"dir. Bu kategoriyi oluşturan ifadeler şu şekildedir.

"İletişim arabaya benzer; Çünkü arabada iletişim gibi bir ihtiyaçtır." ( Eğgitim17)

"İletişim arabaya benzer; Çünkü bir şeye ulaşmak için aracı olur." ( $\dot{\mathrm{I}}_{\text {Idaris }}$ )

"İletişim trene benzer; Çünkü her vagon bir iletişim aracı gibidir." ( $\left.\mathrm{M}_{\text {ühendislik6 }}\right)$ 


\section{SONUÇ ve TARTIŞMA}

Araştırmada öğrenciler, iletişimi en fazla "temel ihtiyaca, doğa olaylara, uzunluğa, sonsuzluğa; en az ise ulaşılması gereken yere, coğrafyaya ve taşıtlara benzetmektedir. Üniversite öğrencilerine göre, iletişim günlük ihtiyaçları karşılamada bir gereksinim olmakta ve yaşamın devamlllı̆̆ için büyük önem teşkil etmektedir. Bireyler iletişim yoluyla duygu ve düşüncelerini yaşadığı topluma aktarmaktadır. Birey için bu bir temel ihtiyaçtır. Maslow (1954)'a göre bireyin temel ihtiyaçlarının karşılanması, bireye psikolojik, sosyolojik, fizyolojik vs. yararlar sağlamaktadır. Beşikten mezara bu ihtiyaçlar karşılanırken, bütün süreçte birey çevresiyle etkileşim ve iletişim içerisinde bulunmaktadır (Topaloğlu, 2013; Dökmen, 2011;Tanrıkulu, 2009). Mesela kaygıll, stresli, kendisini güvende hissetmeyen ve ya saygı ve sevgi beklentisi içerisinde olan bireyler başka bireylerin desteğine ve yardımına ihtiyaç duymaktadır. Birey bu ihtiyacı iletişim kanalları ile gerçekleştirmektedir. Bunlar, kaynak, mesaj, kanal, alıcı ve geribildirimdir. Birey için kaynak bazen bir aile üyesi bazen öğretmen bazen de akran grubu olabilmektedir. Kaynak birey için iletişimi başlatan, duygu ve düşünceleri mesajlar yoluyla alıcıya ileten kişilerdir. Eğitim sisteminde kaynak daha çok öğretmen olmaktadır. Öğretmenin bilgi, becerisi, kullandığı sözcükler, jest-mimikler vs. birey için birer kaynak niteliğindedir (Gökçe, 1998; Eren, 1998; Gürgen, 1997). Tabi kaynağın bu bilgileri alıcıya ulaştırması beklenir. Bunu da mesaj yoluyla gerçekleştirmektedir. Mesaj, kaynaktan aldığı iletileri alıcıya aktarma yoludur. Bu mesajlar bireye aktarılırken yazılı, sözlü, sözsüz birçok kanal kullanılmaktadır (Gökçe, 1998). Kanallar yoluyla gelen iletiler/uyarıcılar alıcıya ulaştırılmaktadır. Tutar ve Yılmaz (2008)'a göre alıcı, mesaj içeren işaretleri algılar, onları belleğinde anlamlı hale getirerek kodlar, daha sonra iletişim sürecini sonlandırır ve ya kendisi bir ileti göndererek kaynak rolüne geçer ve iletişimi devam ettirir. İletişim süreci, gönderilen mesaj, alıcının onu algılaması ile son bulmamaktadır. İletişimde kurulan bütün bu sürecin verimli geçip geçmediği hakkında bildirimler sağlanmalıdır. Başka bir deyişle, kaynak, mesaj, kanal, alıcı arasında kurulan bağla ilgili etkiler, tepkiler hakkında bilgi verilmelidir. Bu iletişimin sürekliliği için önemlidir. İletişimin temel amacı da Eyicil ve Can'ın (1999) belirttiği gibi, bireyler arasında karşıılıklı bilgi alışverişinde bulunmasını sağlamaktır. Bireyler arasında kurulan karşıllıklı iletişim bireylerin birbirlerini tanımasına, anlamasına ve yaşadığı dünyayı keşfetmesine yardımcı olacaktır. Farklı şeyleri keşfeden birey, yaşadığı dünyadan mutluluk duyacak ve haz alacaktır. Mutluluk duygusuyla iletişim, birey için yaşadığı coğrafya, kültür, bazen sürekli etkileşimde olduğu bir nesne, bazen birey için öğretmenin öğrencisiyle-veliyle, doktorun hastasıyla, işçinin işverenle vs. kurduğu bağ olarak tanımlanacaktır. Çünkü bireyler sevdikleri ya da sevmedikleri olayları, duyguları ve düşünceleri yakın çevresindeki nesnelere, durumlara benzetmektedir. Bilişsel yapılarındaki bu nesneleri duygu ve düşünceleriyle ilişkilendirmektedir. Gördükleri, duydukları, etkileşimde bulundukları her şeyi iletişimle açıklamaktadır.

\section{Öneriler}

- Öğretmen adaylarının iletişim becerilerinin mesleki becerilerine katkıları farklı bölümler dikkate alınarak araştııılabilir.

- İletişim becerilerin akademik başarılarına katkılarına ilişkin nitel ve nicel çalışmalar yapılabilir.

- İletişim becerilerin hangi üst düzey becerilere etki ettiğine ilişkin farklı sınıf seviyeleri/yaş dikkate alınarak araştırılabilir.

\section{KAYNAKÇA}

Alper, D. (2007). Psikolojik danışmanlar ve sınıf öğretmenlerinin duygusal zeka düzeyleri-iletişsim ve empati becerilerinin karşılaştırılması. Yayımlanmamış Yüksek Lisans Tezi, Dokuz Eylül Üniversitesi, İzmir.

Akın, M. \& Aydemir, M. (2007). Üniversitede okuyan kız öğrencilerin cinsiyet rolü tutumları bağlamında aile ve evlilik kurumlarına bakışları. Selçuk Üniversitesi Fen Edebiyat Fakültesi Edebiyat Dergisi, 18, 43-60.

Aksungur, G. (2018). Türkçe öğretmenlerinin sınıf içi etkili iletişim becerileri algılarının incelenmesi. Yayınlanmamış Yüksek Lisans Tezi, Ahi Evran Üniversitesi, Sosyal Bilimler Enstitüsü, Kırşehir.

Avşaroğlu, S. (2011). Aile içi ilişkiler ve iletişim. (Editör:Alim Kaya). Kişilerarası ilişkiler ve etkili iletişim İstanbul: Pegem Akademi Yayınları.

Balcı, S. \& Yılmaz, M. (1999). Çocukları anaokuluna devam eden annelere verilen iletişim becerileri eğitiminin ailenin işlevlerine etkisi. Türk Psikolojik Danışma ve Rehberlik Dergisi, II (14).

Baran, A. (2013). Genç ve gençlik: Sosyolojik Bakış. Gençlik Araştırmaları Dergisi, ISSN: 2147-847 
Çiftçi, S. \& Taşkaya, S. M. (2010). Sınıf öğretmeni adaylarının öz yeterlilik ve iletişim becerileri arasındaki ilişki. e-Journal of New World Sciences Academy, 5(3), 921-928.

Doğan, C. (2013). Ailede iletişsim sanatı. İstanbul: Kalbi Kitaplar

Dökmen, Ü. (2011).Sanatta ve günlük yaşamda iletişim çatışmaları ve empati. (45.basım). İstanbul: Remzi Kitabevi:

Eren, E. (1998). Yönetim ve organizasyon (4.Baskı). İstanbul:Beta Yayınları.

Ergen, H. (Ocak, 2001).Öğretmenlerin toplumsal konumlarl ve rolleri. (Online). $<$ http://www.yunus.hacettepe.edu.tr/hergen/edusos/öğretmen_rolleri.htm. (Erişim Tarihi, 10.04.2018).

Eyicil, A \& Can, N. (1999). İnsan ilişkileri. (4. Basım) Ankara: Gün Yayıncılık.

Gökçe, O. (1998). Iletişim bilimine giriş. Ankara: Turhan Kitabevi.

Gürgen, H. (1997). Örgütlerde iletişim kalitesi. İstanbul: Der Yayınları.

Kloth, S., Janssen, P., Kraaimaat, F.\& Brutten, G.J. (1998). Communicative sytles of mothers interacting with their preschool-age children: a factor analytic study. Journal of Child Language, 25 (1), 149-168.

Leibowitz, J., Ramos-Marcuse, F. \&Arsenio, W. F. (2002). Parent-child emotion communication, attachment and affective narratives. Attachment \& Human Development, 4 (1), 55-67.

Maslow, A. H. (1954). Motivation and personality. New York: Harper \& Row, Publishers.

Miles, M. B.,\&Huberman, A. M. (1994). Qualitative data analysis: an expanded source book. London, United States of America: SAGE.

Özden, Y. (2003). Öğrenme ve ögretme. Ankara: Pegem Yayınları.

Özkan, Z. (2004). NLP teknikleriyle aile içi iletişim. Hayat Yayınc1lı: İstanbul.

Öztemel, Z. (2016). Halkla ilişkiler faaliyetlerinde yeni iletişim teknolojilerinin kullanımı: Büyükşehir Belediyeleri üzerine bir araştırma. Yayınlanmamış Yüksek Lisans Tezi, Atatürk Üniversitesi, Sosyal Bilimler Enstitüsü, Erzurum.

Tanrıkulu B (2009). İnsan kaynakları yönetiminin etkinliğinde iletişimin rolü. Çağın Polisi Dergisi, www.caginpolisi.com.tr (Erişim tarihi,4.04.2018).

Temiz, G. (2014). Anne çocuk iletişim becerileri eğitiminin çocukların duyguları tanıma ve ifade etme becerilerine etkisi. Yayınlanmamış Yüksek Lisans Tezi. Selçuk Üniversitesi, Sosyal Bilimler Enstitüsü, Konya.

Topaloğlu, T. (2013). Maslow'un gereksinimler hiyerarşisi kuramı. Erişim: [http://www.emotivasyon.net/Maslow-un-Gereksinimler-Hiyerarsisi-KuramiHierarchy-of-Needs.html]. Erişim Tarihi: 14.10.2013.

Tutar, H. ve Yılaz, M. K. (2008). Genel iletişim kavramlar ve modeller. (6. Basım) Ankara: Seçkin Yayıncılık.

Saban, A. (2009). Öğretmen adaylarının öğrenci kavramına ilişkin sahip oldukları zihinsel imgeler. Türk Eğitim Bilimleri Dergisi, 7(2).

Ulukan, H. (2017). Yönetim tarzlarının beden eğitimi ve spor yüksekokullarındaki informal iletişsim kanallarına etkisi. Yayınlanmamış Doktora Tezi, Sakarya Üniversitesi, Eğitim Bilimleri Enstitüsü, Sakarya.

Üstünsel, G. (2011). Etkili iletişsim becerileri ve beden dili. Yayınlanmamış Yüksek Lisans Tezi, Namık Kemal Üniversitesi, Fen Bilimleri Enstitüsü, Tekirdağ.

Ün, A. (2014). Sağllk kurumlarında yönetici ve diğer sağllk personeli arasındaki iletişim sorunları (Tire Devlet Hastanesinde bir uygulama). Yayınlanmamış Yüksek Lisans Tezi, Beykent Üniversitesi, Sosyal Bilimler Enstitüsü, İstanbul.

Yıldırım, A.\& Şimşek, H. (2013). Sosyal bilimlerde nitel araştırma yöntemleri. Ankara: Seçkin Yayıncılık. 


\title{
University Students' Metaphorical Perception about the Concept of Communication
}

\author{
Sevda KOÇ AKRAN \\ Siirt University, Siirt/TÜRKIYE \\ e-posta:sevdakc@gmail.com \\ Merve ACIDEMIR \\ Siirt University, Siirt/TÜRKIYYE \\ Şevval ULUDAĞ \\ Siirt University, Siirt/TÜRKIYE
}

Citation: Koç Akran, S., Acıdemir, M., \& Uludağ, Ş. (2018). University Students' Metaphorical Perception about the Concept of Communication. E-Kafkas Journal of Educational Research, 5(2), 69-82.

\section{Extended Summary}

\section{Purpose}

The main aim of this research is determine university students' metaphorical perception about the concept of communication.

\section{Method}

The study group of the research in which the qualitative research is used is composed of 340 students attending Siirt University in the department of Economics and Administrative Sciences, Faculty of Arts and Sciences, Faculty of Education, Department of Theology, Veterinary, Medicine, Physical Education and Sports, Siirt School of Health, School of Foreign Languages, Interpreting and Engineering Department.

In this research "phenomenology" is used as one of the qualitative research methods. Phenomenology focuses on the phenomena that people are aware of them in the surrounding environment but they do not have a deep understanding of them. There are many problems, experiences and perceptions in the environment that people live in. People's memories do not record all of these stimuli in the environment they live. Phenomenology is an effective method in determining people's level of awareness.

Research data have been collected through forms in which open-ended questions are included. Research data have been collected from the students who have participated in this research in the department of Economics and Administrative Sciences, Faculty of Arts and Sciences, Faculty of Education, Department of Theology, Veterinary, Medicine, Physical Education and Sports, Siirt School of Health, School of Foreign Languages, Interpreting and Engineering Department. An open-ended form was prepared to determine the perceptions of the students who participated in the research on the concept of "communication". They are asked to complete the sentence of "Communication is like... because...". Two ways are applied to carry out the research reliably and to increase its validity. These are allowing 15 minutes each student participating in the study and giving a similar metaphor example to each student in the study group.

Content analysis is done on the data obtained at the end of the study. The main aim in content analysis is to reach concepts and relationships that can explain the collected data. Data collected for this purpose are need to be conceptualized firstly, and then organized in a logical way according to the emerging concepts and accordingly to identify the themes describing the data. developed.

During the analysis and interpretation of the data, there are two different stages that the study group has

A. Coding and Sorting

B. Compiling example metaphor

C. Developing categories

D. Ensuring validity and reliability

E. Transferring data to computer environment

In order to determine whether metaphors given under the twenty conceptual categories reached in the research represent a particular conceptual category expert opinion is consulted. Experts are given two lists and the first list contains 133 metaphors arranged in alphabetical order and the second list contains names and characteristics of twenty different conceptual categories. The experts have matched example metaphor list in the 
first list with twenty conceptual categories in the second list using these two lists. Then, the matches made by the expert have been compared with the researchers' own categories. In the comparisons, the number of consensus and difference of opinions were determined and the reliability of the research is calculated using Miles ve Huberman's (1994: 64) formula "Reliability=(Consensus):(Consensus + difference of opinions))x100". In qualitative studies, when the harmony between expert and researcher ratings is 0.93 and above reliability at the desired level is ensured. (Saban, 2009).

\section{Conclusion and Discussion}

The results obtained in the study, the participants' metaphors for the concept of communication respectively and the most belong to categories of "Basic need", "Information source", "Nature events", "Communication" "Length", "Being infinite". The categories represented least are "Place to be reached", "To be in harmony", "Geography", "Vehicles" and "Bad". Perceptions about the concept of communication skills of university students are given below.

According to university students in the "basic need" category, it is seen that participants state that communication is a necessity to meet daily needs and the greatest condition for the continuity of life. The reason why communication is chosen as the basic necessity of our lives is communication is the most important tool in conveying emotion, thought, news, and information among people.

- When examining the metaphor statements that constitute the "information source" category, participants state that information source for the concept of communication is means of communication and all information is available in these means and that it requires to have the ability to use communication tools to reach knowledge. Why communication is chosen as the "source of information" is that sources of communication are needed to communicate.

- In the "Length" category, it is seen that participants state that communication is everywhere and connected to everything and the communication may also be incomplete when the connection is broken.

- In the "infinite" category, it is seen that participants state that the concept of communication has depth and it is literary.

- Metaphors examples used least in the study; in the category represented by the least metaphor, metaphor produced by 1 student is "in harmony" category. It is seen that communication is stated as spiritual.

- Metaphor produced by 3 students is seen to be stated as communication causes addiction and dissuasion in the "bad" category.

- In general, according to the results obtained in the research, while Siirt University education faculty students produce metaphors about communication as "Basic need" and "Infinite", students of theology faculty do it as "Length" and "Basic need". Science and literature faculty students produce metaphors about communication as "Bad" and "Geography". Health Academy students produce metaphors about communication as "The place to be reached" and "Nature events". 